\title{
Perception and Behavior of PIDC Patients Towards Online Dental Health Information
}

ISSN: 2637-7764

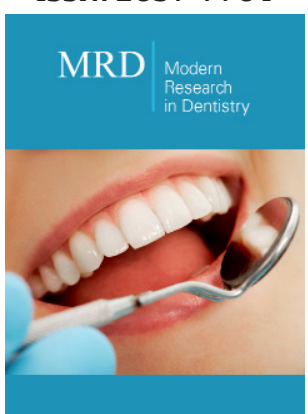

*Corresponding author: Philip Pradeep, Lecturer, Department of Conservative Dentistry \& Endodontics, Penang International Dental College, Penang, Malaysia

Submission: 制September 15, 2021

Published: 褿October 21, 2021

Volume 6 - Issue 5

How to cite this article: Jalison Jacob Cheruvathoor, Philip Pradeep, Deevisha Raj, Choo Qi En, Nicholette Tan Cheng Lynn. Perception and Behavior of PIDC Patients Towards Online Dental Health Information. 6(5). MRD. 000649. 2021. DOI: 10.31031/MRD.2021.06.000649

Copyright@ Philip Pradeep, This article is distributed under the terms of the Creative Commons Attribution 4.0 International License, which permits unrestricted use and redistribution provided that the original author and source are credited.

\author{
Jalison Jacob Cheruvathoor ${ }^{1}$, Philip Pradeep ${ }^{1 *}$, Deevisha Raj ${ }^{2}$, Choo Qi En ${ }^{2}$ and \\ Nicholette Tan Cheng Lynn² \\ ${ }^{1}$ Lecturer, Department of Conservative Dentistry \& Endodontics, Penang International Dental \\ College, Penang, Malaysia \\ ${ }^{2}$ Year 5 student, Penang International Dental College, Penang, Malaysia
}

\begin{abstract}
Background: The Internet represents an increasingly common source of dental health related information, and it has facilitated a wide range of interactions between patient and the oral health care providers.
\end{abstract}

Aim: To evaluate the perception and behaviour of Penang International Dental College (PIDC), Penang, Malaysia patients towards online dental health information.

Methodology: A pre validated questionnaire was randomly distributed to 365 new and existing patients of PIDC attending treatment at the facility during the years 2019-2020. Convenience sampling was carried out for patients attending PIDC for their treatment. Statistical analysis: T-test was used to find the significant difference between the younger users $(<35)$ and the older users (36-75) pertaining to using the internet for seeking dental health information. Furthermore, Pearson's correlation was applied to correlate the relationship between age and the frequency of internet use for seeking dental information.

Result: PIDC has a satisfactory number of patients (268) who use the internet for seeking dental health information. The patients have a positive perception towards the online dental health information gathered with a mean score of 28.7. There is a significant difference between the younger users $(<35)$ and the older users (36-75) pertaining to using the internet for seeking dental health information $(\rho<0.05)$. There is a significant relationship between age and the frequency of internet use for seeking dental information $(\rho<0.05)$.

Conclusion: PIDC does have a satisfactory number of patients who use the internet for seeking dental health information with a positive perception towards the information gathered.

Keywords: Internet; Dental health information; Perception; Behavior

\section{Introduction}

The Internet represents an increasingly common source of dental health related information, and it has facilitated a wide range of interactions between patients and oral health care providers. With easy access to the Internet these days, patients are able to gain an insight of their dental related signs \& symptoms as well as information on maintaining good oral health. Information seeking behavior has an impact on the provider-patient communication, patient health status and quality of care remains an area of further inquiry, particularly in dentistry. Dental practice-based research networks (PBRNs) offers an ideal setting to assimilate dental advances and treatment decisions into practice as well as improving patient care altogether. The advantages include PBRN practitioner-investigators bringing practice relevant topics into the research agenda and engaging in the study development process. Information seeking refers to the "purposeful seeking for information as a consequence of a need to satisfy some goal." Since 2000, Internet popularity for seeking health information has 
widely increased. A Pew survey in 2000 showed that 55 percent of American adults use the Internet to acquire health information [1]. Dental health information sought online by patients is not intended to replace dentists, but rather, to support it. Using the Internet to search for health information has many advantages: easy access, availability of a wide range of illustrated and audiovisual health resources, as well as providing an opportunity to ask experts' opinion [2]. Reasons for dental health seeking include the following: to know the dental pattern practiced by dentists, using personal judgment to make decisions regarding the treatment, and gathering information and experience from others [3].

\section{Material and Method}

A cross sectional study was designed and conducted in the form of questionnaire. The questionnaire we have used in our research was adapted from a previous study done in Scotland. Before distribution of the questionnaire, validation was done. The sample size was set at 365 participants seeking treatment at PIDC in the time frame of 2019-2020. Convenience sampling was carried out for patients attending PIDC for their treatment. The questions are closed response and participants were asked to select one response from a range of categorical options. Patients had a choice to participate in the physical copy or our online questionnaire version which was conducted on Google Form at their convenience. The questionnaire was also available in Bahasa Malaysia for participants who preferred to answer questions in the local language. The data collected was entered into SPSS 16 and analyzed. The characteristics of the sample were analyzed and illustrated by descriptive means. T-test was used to find the significant difference between the younger users $(<35)$ and the older users (36-75) pertaining to using the internet for seeking dental health information. Furthermore, Pearson's correlation was applied to correlate the relationship between age and the frequency of internet use for seeking dental information.

\section{Result}

According to the Table 1, 268 or $73 \%$ of the respondents have used the internet to seek dental information whereas 96 or $26.2 \%$ of them have not used the internet to search for dental information.

Table 1: Number of patients who use the internet for seeking dental health information.

\begin{tabular}{|c|c|c|c|}
\hline \multirow{2}{*}{$\begin{array}{c}\text { Used Internet } \\
\text { to Find Dental }\end{array}$} & Yes & 268 & 73 \\
\cline { 2 - 4 } Information & No & 96 & 26.2 \\
\cline { 2 - 4 } & Total & 364 & 99.2 \\
\hline
\end{tabular}

According to the Table 2, majority of the patients, 142 or $38.7 \%$, went online because they had developed some dental problems.
Only 33 or $9 \%$ of the respondents appeared to be checking out on the new medicines prescribed and treatment suggested.

Table 2: Reasons for seeking health information online.

\begin{tabular}{|c|c|}
\hline Reason & Total \\
\hline Noticing new symptoms or change in my mouth & 142 \\
\hline Finding/ selecting a dentist or dental clinic & 49 \\
\hline Preparing for a dentist's consultation & 62 \\
\hline Being diagnosed with a dental condition not familiar to me & 42 \\
\hline Being prescribed with a new medication, test, or treatment & 33 \\
\hline Having doubts about information given by my dentist & 49 \\
\hline Dealing with an ongoing dental problem & 88 \\
\hline $\begin{array}{l}\text { Deciding to change my behaviors/ daily routine (e.g. diet, quit } \\
\text { smoking) }\end{array}$ & 43 \\
\hline $\begin{array}{l}\text { Hearing or seeing something in the news that you wanted to } \\
\text { learn more about }\end{array}$ & 91 \\
\hline For knowledge or curiosity & 110 \\
\hline Others (please specify): & 2 \\
\hline
\end{tabular}

As found in our study, a total of 131 or $35.7 \%$ of the respondents did discuss with their dentist, the information that they found online. Whereas 191 or $52 \%$ of the respondents did not discuss with their dentist regarding the online information they found (Table 3).

Table 3: Discussing Dental Health Information with Dentist.

\begin{tabular}{|c|c|c|c|}
\hline & $\begin{array}{c}\text { Respondent's } \\
\text { answer }\end{array}$ & $\begin{array}{c}\text { N=322 } \\
\text { Frequencies }\end{array}$ & Percentage \\
\hline \multirow{2}{*}{$\begin{array}{c}\text { Discussing with } \\
\text { dentist about dental } \\
\text { health }\end{array}$} & Yes & 131 & 35.7 \\
\cline { 2 - 4 } & No & 191 & 52 \\
\cline { 2 - 4 } & Total & 322 & 87.7 \\
\hline
\end{tabular}

Based on the Table 4, the respondents have a mean score of 28.7 in terms of the positivity of their perception towards online dental health information.

Table 4: Patient's Perception towards Online Dental Information.

\begin{tabular}{|c|c|c|}
\hline \multirow{2}{*}{$\mathbf{N}$} & Valid & 319 \\
\hline & Missing & 48 \\
\hline & Mean & 28.8621 \\
\hline & Median & 29 \\
\hline & Mode & 27 \\
\hline & Std. Deviation & 7.15021 \\
\hline & Range & 36 \\
\hline & Minimum & 9 \\
\hline & Maximum & 45 \\
\hline
\end{tabular}


The number of respondents who use the internet in the $<35$ years age group was 136 whereas only 44 people in the age group of 36-75 years had used the internet. The two means were subjected to a t-Test to find out if there existed any significant difference between them Table $5 \mathrm{a}$.

Table 5a: Means of Use of Internet of Age Groups $<35$ and 36-75.

\begin{tabular}{|c|c|c|}
\hline Age (years) & $\mathbf{N}$ & Usage (\%) \\
\hline$<35$ & 136 & 37.1 \\
\hline $36-75$ & 44 & 12 \\
\hline
\end{tabular}

According to the Table $5 b$, the $\rho$ value obtained is 0.000 . It is evident that there is a clear significant difference between the two age groups.

Table 5b: t-test of use of internet score between the $<35$ years and the 36-75 years age group.

\begin{tabular}{|c|c|c|}
\hline $\mathbf{t}$ & df & Sig. ( $\rho$ value) \\
\hline-3.977 & 178 & 0 \\
\hline
\end{tabular}

\section{Discussion}

\section{Number of patients who use the internet for seeking dental health information.}

From our study`s findings it is indicated that $73 \%$ of patients used the internet for seeking online dental information. It is noteworthy that such a high percentage of PIDC patients are internet savvy. This implies that there is a great potential of the Internet as an important channel for health information and support for the general population.

\section{Reasons for seeking health information online}

Table 2 depicts the reasons for seeking health information online. It must be admitted that patients may have multiple reasons to check online dental resources. The table shows that most of them $(142 \%$ or $38.7 \%)$ went online because they had some dental problems. Sillence [4] found that an increasing number of people (especially women) turned to the Internet for health advice, and then combined online advice with offline advice from friends, family and doctors in order to be confident in their final decision. In fact, according to Sillence [4], women believe that the Internet influences their decision-making and improves communication with doctors [5].

\section{Discussing dental health information with dentist}

Table 3 shows that a total of 131 or $35.7 \%$ of the respondents did discuss with their dentist, the information that they found online. In the early days, because dentists were only a source of information about the health of patients, they used to have confidence in dentists and usually followed their recommendations. However, the situation has now changed, and patients can also use the Internet to obtain health-related information and to evaluate the dentist's recommendations for diseases. A study conducted by Ball and Lillis found similar results. A study conducted by Chestnutt and Reynolds found different results. Despite using the Internet, most patients still believe that dentists are the most reliable source of oral health information.

\section{Patient's perception towards online dental information}

Based on Table 4 above, the respondents have a mean score of 28.7 in terms of the positivity of their perception towards online dental health information. The mean score of 28.7 works out to $64.1 \%$ when computed against the maximum possible mean. Thus, the respondents' perception towards online health information is sufficiently positivity. According to Chestnutt, Ivor and Reynolds, K. in their examination, discovered that patients who looked for online data were generally better informed and in fact information on the Internet has influenced and enhanced the delivery of oral care. They also found that the internet was an asset and not a threat to the dentist-patient relationship. The internet information had actually led to patients demanding inappropriate care or more complex treatment.

(a) Means of use of internet of age groups $<35$ and 36-75

(b) t-Test of use of internet score between the $<35$ years and the 36-75 years age group

Table 5 shows the existence of a significant difference between the use of internet for online dental health information seeking aged less than 35 and those aged between 36-75 years old. The age group of less than 35 have a higher online dental information seeking score. It was established that, age certainly impacts the online dental information seeking score clearly indicating that advancing age may mean a reduced inclination of searching dental health information online. The difference between the younger and the older group was subject to a t-Test, to find out if the difference was minimal and negligible. However, the results indicated that the difference was significant.

\section{Relationship between age and the frequency of internet use}

As shown in Table 6 there is a strong negative correlation between the frequency of use of the internet to seek online dental information and the age, $(r=-0.524, \rho<0.05)$. This means that the frequency of use of the internet to seek online dental information has an inverse relationship with age. Higher age corresponds with lower frequency of internet use and vice versa. Clearly the younger respondents have a higher frequency of internet use and this would certainly translate into a higher rate of online dental information seeking. 
Table 6: Relationship between age and the frequency of internet use.

\begin{tabular}{|c|c|c|c|}
\hline \multirow{2}{*}{ Age } & N=365 & Age & 1 \\
\hline \multirow{2}{*}{ Frequency of Internet Use } & Pearson Correlation & $-0.524^{*}$ & 0 \\
\cline { 2 - 4 } & Sig. (2-tailed) & $-0.524^{*}$ & 0 \\
\cline { 2 - 4 } & Pearson Correlation & 0 \\
\hline
\end{tabular}

As can be seen from the table above, alpha ( $\rho$ value) is less than 0.05 , and the Pearson ' $r$ ' value is -0.524 .

\section{Conclusion}

The Internet has great potential to affect health and wellness. By providing information about health and wellness services and supporting self-help and patient choice, it can and most definitely will increasingly be used to educate and enhance public capabilities. Overall, participants showed awareness of potential issues related to online health information searches. The findings of this study point to a series of barriers to online health information between patients and doctors and factors that facilitate communication. This study emphasizes the need to enhance patients' communication skills, eHealth literacy assessments, and targeted resources to enable individuals to obtain high-quality and reliable online health information, and to remind patients of the importance of consulting medical professionals when using online health diagnosis and resources for treating health problems. The use of the Internet by practitioners needs to be promoted and developed to maximize its potential benefits to patients.

\section{Perception \& behavior of PIDC patients towards Online Dental Health Information Seeking}

We would like to ask for your opinion and your experience of using the Internet for health-related information. There are no right or wrong answers, choose an answer that suits you the most.

Please check the appropriate answers, or write your answers in the spaces provided:

Can you tell us some basic information about yourself?

1. Age
$18-25$
$\square$ 26-35
$36-45$
46-55
$56-65$
$66-75$

2.

\section{Gender}

Male

$\square$ Female

3. Occupational status

$\square$ Full-time employment
$\square$ Full-time student
$\square$ Retired

$\begin{array}{lll}\square \text { Part-time employment } & \square \text { Self-employed } \\ \square \text { Part-time student } & \square \text { Unemployed }\end{array}$

Others(please specify):

\section{Do you use the Internet?}

$\square$ Yes $\square$ No
If NO, Thank you, this is the end of the survey. 
5. How often do you use Internet?

$\begin{array}{lll}\square \text { Once a year or less } & \square \text { Every few months } & \square \text { Once a month } \\ \square \text { Several times a month } & \square \text { Once a week } & \square \text { Everyday }\end{array}$

6. Have you ever used Internet to find dental health related information?
$\square$ Yes
No

If NO, Thank you, this is the end of the survey.

7. How often do you use Internet to find dental health information?
$\square$ Once a year or less
Every few months
$\square$ Once a month
Several times a month
$\square \quad$ Once a week
Several times a week
Everyday

8. Did you find the dental health information for... (Please check all that apply)

$\square$ Myself $\square$ Friends/Co-workers $\square$ Family members

Please specify:

9. Which tool did you use to look for dental health information online? (Please check all that apply)
$\square$ Desktop computer
Laptop computer
$\square$ Tablet
$\square$ Smartphone

10. What kind of dental health information have you ever found online? (Please check all that apply)
$\square$ Symptom
$\square$ Disease/ Condition
$\square$ Service info (e.g. dentist, dental clinic)
$\square \quad$ Medication
$\square$ Test/ Investigation
$\square$ Treatment and procedure
$\square \quad$ Chinese medicine
$\square$ Alternative medicine
$\square$ Vitamins and supplements
$\square \quad$ Health insurance
$\square$ Healthy behaviors (e.g. diet, quit smoking)
Others(please specify):

11. Why did you find dental health information online? (Please check all that apply)
$\square \quad$ Noticing new symptoms or change in my mouth
$\square \quad$ Finding/ selecting a dentist or dental clinic
$\square \quad$ Preparing for a dentist's consultation
$\square \quad$ Being diagnosed with a dental condition not familiar to me
$\square \quad$ Being prescribed with a new medication, test, or treatment
$\square \quad$ Having doubts about information given by my dentist
$\square \quad$ Dealing with an ongoing dental problem
$\square \quad$ Deciding to change my behaviors/ daily routine (e.g. diet, quit smoking)
$\square \quad$ Hearing or seeing something in the news that you wanted to learn more about
$\square \quad$ For knowledge or curiosity
$\square \quad$ Others (please specify): 
12. On which websites did you find the dental health information? (Please check all that apply)

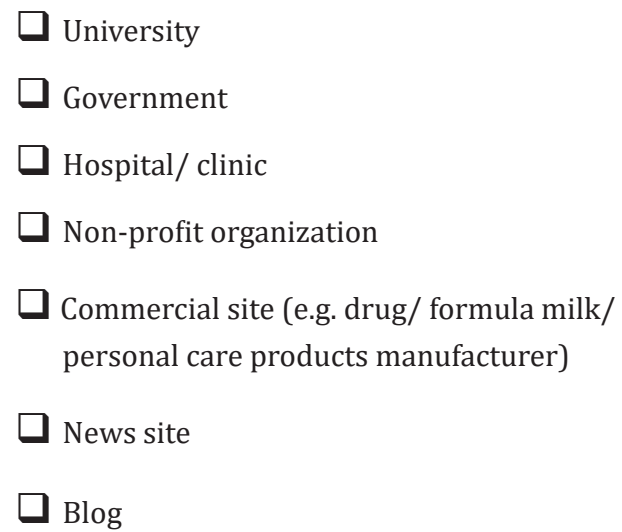

$\square$ Online encyclopedia (e.g. Wikipedia)

$\square$ Q\&A site (e.g. Yahoo! Answers, Baidu Knows)

$\square$ Internet forum/ message board

$\square$ Social media (e.g. Facebook, Twitter)

$\square$ Health portal/ medical encyclopedia (e.g. MIMS,

PubMed, MedlinePlus, WebMD)

Video-sharing site (e.g. YouTube)

Others (please specify):

13. Why did you choose those websites to find the dental health information? (Please check all that apply)

Recommended by specialists

Recommended by family or friends

$\square$ Top results from search engines
$\square$ Easy to understand
Usual habit
I think it's trustworthy
$\square$ Convenience

$\square$ Others (please specify):

14. Did you ever ask or discuss with your dentist about the dental health?

$\square$ Yes

$\square$ No

15. Did you ever share with your dentist regarding dental health information found online?(e.g. by email/ print-out/ photos or screenshot on smartphone)

16. Did you ever ask or discuss with your dentist about specific oral disease or diagnosis because of the dental health information found online?

17. Did you ever ask or discuss with your dentist about specific treatment, tests or referral because of the dental health information found online?

18. Was your dentist interested in hearing about the dental health information you found online?
$\square$ Very interested
$\square$ Not at all interested
$\square$ Slightly interested
口 Don't know/ Can't remember 
19. For the following statements, please tick ' $\checkmark$ ' the responses that best reflect your opinion and experience now.

\begin{tabular}{|c|c|c|}
\hline $\begin{array}{l}\text { Strongly } \\
\text { disagree }\end{array}$ & Dis & Undecided \\
\hline
\end{tabular}

(a) I know what dental health resources are available on the Internet.

(b) I know where to find helpful dental health resources on the Internet.

(c) I know how to find helpful dental health resources on the Internet.

(d) I know how to use the Internet to answer my questions about dental health.

(e) I know how to use the dental health information I find on the Internet to help me.

(f) I have the skills I need to evaluate the dental health resources I find on the Internet.

(g) I can tell high quality dental health resources from low quality dental health resources on the Internet.

(h) I feel confident in using information from the Internet to make dental health decisions.

(i) I trust the online information more than my dentist.

\section{References}

1. Ahadzadeh AS, Sharif SP (2019) Internet and Technology. Pew Research Center: Internet, Science \& Tech.

2. Ghweeba M, Lindenmeyer A, Shishi S, Abbas M, Waheed A, et al. (2017) What predicts online health information-seeking behavior among Egyptian adults? a cross-sectional study. Journal of Medical Internet Research 19(6): e216.
3. Li J, Theng YL, Foo S (2016) Predictors of online health information seeking behavior: Changes between 2002 and 2012. Health Informatics Journal 22(4): 804-814.

4. Sillence E, Briggs P, Harris PR, Fishwick L (2007) How do patients evaluate and make use of online health information? Social Science \& Medicine.

5. Chestnutt IG, Reynolds K (2006) Perceptions of how the Internet has impacted on dentistry. Br Dent J 200(3): 161-165. 